$\begin{array}{cc}\text { ACADEMIA ROMÂNĂ } & \text { Rev. Roum. Chim., } \\ \text { Reve, 65(3), 269-275 } \\ \text { Reve Roumaine de Chimie } & \text { DOI: } 10.33224 / \text { rrch.2020.65.3.06 } \\ \text { http://web.icf.ro/rrch/ } & \end{array}$

\title{
EXCESS MOLAR VOLUMES AND PARTIAL MOLAR VOLUMES FOR BINARY MIXTURES PROPANOIC ACID WITH 1-PROPANOL, 2-PROPANOL, 1-BUTANOL AND 1-PENTANOL
}

\author{
Mona GEORGESCU, Viorica MELTZER and Elena PINCU*
}

University of Bucharest, Faculty of Chemistry, Department of Physical Chemistry, Bd. Regina Elisabeta 4-12, Bucharest, Roumania

Received December 17, 2019

The densities of binary acid - alcohol mixtures were determined experimentally by the pycnometer method for four binary systems: propanoic acid with 1-propanol, 2-propanol, 1-butanol and 1-pentanol at $298,15 \mathrm{~K}$. From the experimental data, excess molar volumes and partial molar volumes were calculated. The partial molar volumes were revealed by the intersection method and the excess molar volumes were fitted using the polynomial equations of Redlich-Kister type. The results indicate the presence of attractive forces between the components and the decrease of the hydrogen bond strength as the length of the alcohol chain increases.

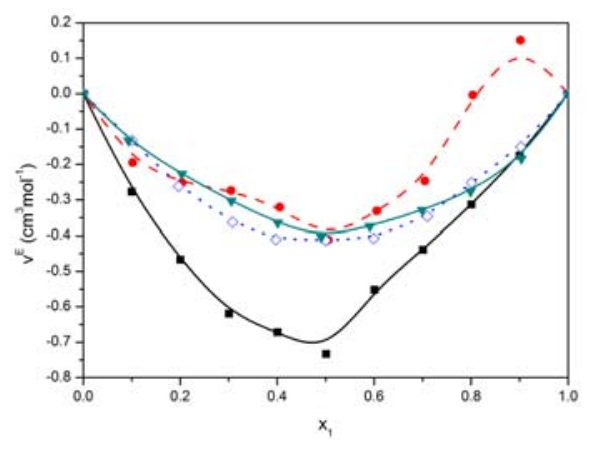

\section{INTRODUCTION}

The thermodynamic characterization of binary systems can be done using thermodynamic properties such as volume, enthalpy, Gibbs free energy, entropy. The thermodynamic excess functions, introduced by Raymond and Scatchard, are quantities that show the deviation from ideal behavior, adapted to the treatment of non-ideal solutions, as well as of a component of such a solution. Excess thermodynamic functions and partial molar quantities are fundamental in the characterization of real systems. With the help of the excess functions it is possible to evaluate the behavior when mixing two miscible components in any proportion. In the case of binary mixtures of liquids, the excess molar volume is used to determine the nature and type of the interactions that take place in the system and can be calculated directly from density measurements.
This work is therefore aimed at determination of excess molar volumes and partial molar volumes in the binary mixtures of 1-propanol, 2propanol, 1-butanol and 1-pentanol with propanoic acid at $25^{\circ} \mathrm{C}$. In addition, the influence of the structure of the alcohol on the excess molar volume, having the same component 1 (propanoic acid) in all systems, was tracked.

Propanoic acid is found in several foods, such as milk, yogurt and cheese. ${ }^{1}$ It is also used as a preservative (E280) because it has antibacterial and antifungal effects. Undigested foods are fermented in the colon and give rise to metabolites, among these metabolites was propanoic acid. Propanoic acid is beneficial to the human body because it lowers fatty acids in the liver, reduces food intake, prevents obesity and type 2 diabetes by improving insulin sensitivity. ${ }^{2-4} 1$-propanol was first discovered in 1853 by Gustave Charles Bonaventure Chancel ${ }^{5}$ and is used as a fuel because it is a flammable liquid. ${ }^{6}$

\footnotetext{
${ }^{*}$ Corresponding author: elena.pincu@chimie.unibuc.ro
} 
2-propanol is the most popular antiseptic, it is found in many disinfectant products (especially those used in hospitals). ${ }^{7,8}$ 1-butanol is present in nature as a result of the fermentation of carbohydrates in some alcoholic beverages, such as beer, wine, whiskey. ${ }^{9,10}$ 1-pentanol is a colorless liquid with an unpleasant odor and is used as a solvent for coating CDs and DVDs. 1-pentanol is a promising alternative fuel for use in diesel engines. ${ }^{11,12}$

\section{RESULTS AND DISCUSSION}

The experimental data obtained for binary mixtures: (propanoic acid +1 -propanol), (propanoic acid +2 -propanol), (propanoic acid + 1-butanol) and (propanoic acid +1 -pentanol) at $25^{\circ} \mathrm{C}$ are presented in tables 1 to 4 . Figures 1 to 4 represent variation of $\mathrm{V}^{\mathrm{E}}$ with $\mathrm{x}_{1}$ (mole fraction of propanoic acid) at $298.15 \mathrm{~K}$. The excess molar volume was fitted with nonlinear Redlich - Kister equation with four parameters and results are presented in table 5. For the systems (propanoic acid +1 -propanol), (propanoic acid +1 -butanol) and (propanoic acid +1 -pentanol) the excess molar volumes decrease with increase of the alcohol concentration, passes through a minimum at about $\mathrm{x}_{2}=0.5$ and then increases with increasing mole fraction of alcohol. This behavior is due to the fact that the hydrogen bond strength between the $-\mathrm{OH}$ and $-\mathrm{COOH}$ groups is higher than that of the same groups. On the other hand, the excess molar volume decreases with the increase of the length of the alcohol chain, this means that the strength of the hydrogen bond decreases.

For the binary mixture propanoic acid + 1propanol the excess molar volume obtained in this work is $-0.733 \mathrm{~cm}^{3} \cdot \mathrm{mol}^{-1}$ at $25{ }^{\circ} \mathrm{C}$ at $\mathrm{x}_{1}=0.5$, a value higher than that obtained in the literature $-0.469 \mathrm{~cm}^{3} \cdot \mathrm{mol}^{-1}$ at $30{ }^{\circ} \mathrm{C}$ but for a mixture of propanoic acid and 1-propanol dried and distilled. ${ }^{13}$

In the case of propanoic acid + 2-propanol system, at the molar fraction 0.5 of 2-propanol, the strength of hydrogen bonds, which is formed between one mole of alcohol and one mole of acid, is the strongest. At values of the mole fractions of 2-propanol less and greater than 0.5 , the strength of hydrogen bonds decreases, because the molar ratio between alcohol and acid changes. ${ }^{14}$ Therefore, if the strength of hydrogen bonds decreases, then the distance between the donor and the acceptor atom will increase, this will be reflected on the excess volume that will decrease. This phenomenon is most evident at $x_{2}=0,1$ (from Figure 2), because the strength of hydrogen bonds decreases most when propanoic acid is in excess.

In the case of the propanoic acid + 1-butanol systems, both the excess molar volumes and the partial molar volumes highlight the presence of attraction forces between the components for all molar fractions as shown in Table 3.

Table 1

Experimental data for propanoic acid (1) + 1-propanol (2) binary system

\begin{tabular}{c|c|c|c|c|c}
\hline $\mathbf{X}_{1}$ & $\boldsymbol{\rho}_{\mathbf{m i x}}\left(\mathbf{g} \cdot \mathbf{c m}^{-\mathbf{3}}\right)$ & $\mathbf{V}\left(\mathbf{c m}^{\left.\mathbf{3} \cdot \mathbf{m o l}^{-\mathbf{1}}\right)}\right.$ & $\mathbf{V}^{\mathbf{E}}\left(\mathbf{c m}^{\left.\mathbf{3} \cdot \mathbf{m o l}^{\mathbf{1}}\right)}\right.$ & $\bar{V}_{\mathbf{1}}\left(\mathbf{c m}^{\mathbf{3}} \cdot \mathbf{m o l}^{-\mathbf{1}}\right)$ & $\bar{V}_{\mathbf{2}}\left(\mathbf{c m}^{\mathbf{3}} \cdot \mathbf{m o l} \mathbf{l}^{\mathbf{1}}\right)$ \\
\hline 1.0000 & 0.992 & 74.681 & 0.000 & 74.681 & 73.246 \\
0.9003 & 0.975 & 74.532 & -0.175 & 74.673 & 73.260 \\
0.8006 & 0.958 & 74.421 & -0.313 & 74.676 & 73.397 \\
0.7008 & 0.940 & 74.321 & -0.439 & 74.630 & 73.598 \\
0.6009 & 0.923 & 74.234 & -0.552 & 74.502 & 73.830 \\
0.5010 & 0.906 & 74.079 & -0.733 & 74.178 & 73.979 \\
0.4009 & 0.886 & 74.167 & -0.672 & 73.935 & 74.322 \\
0.3008 & 0.866 & 74.246 & -0.619 & 73.485 & 74.573 \\
0.2006 & 0.845 & 74.424 & -0.467 & 72.903 & 74.806 \\
0.1003 & 0.824 & 74.641 & -0.277 & 72.094 & 74.925 \\
0.0000 & 0.802 & 74.944 & 0.000 & 71.070 & 74.944 \\
\hline
\end{tabular}




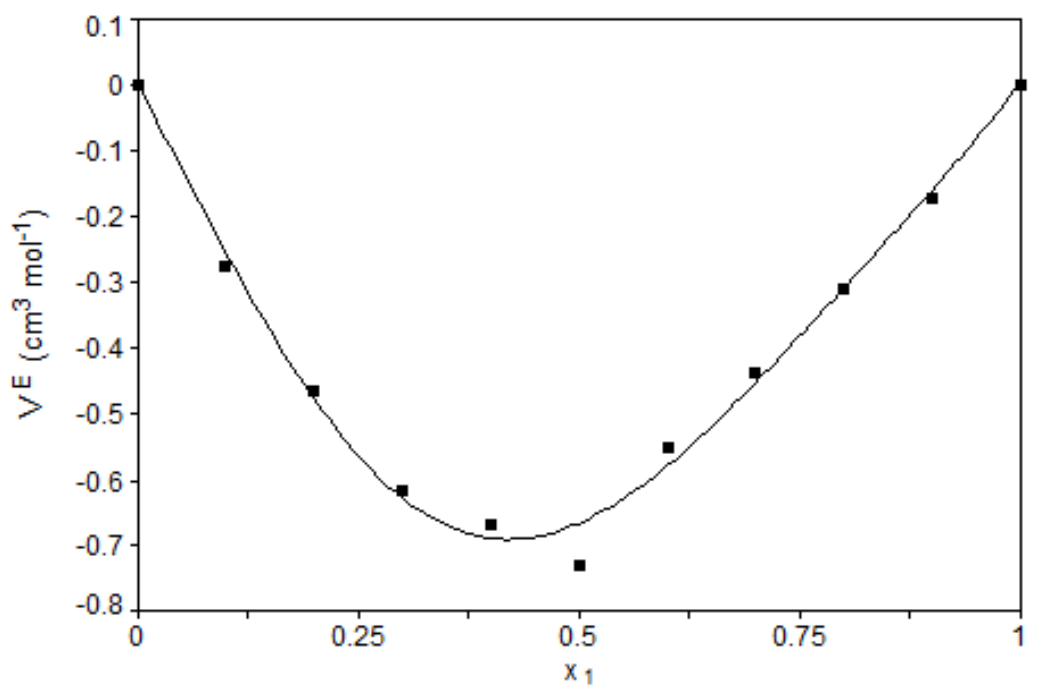

Fig. 1 - Redlich-Kister representation for propanoic acid + 1-propanol binary system.

Table 2

Experimental data for propanoic acid (1) + 2-propanol (2) binary system

\begin{tabular}{|c|c|c|c|c|c|}
\hline $\mathrm{x}_{1}$ & $\rho_{\text {mix }}\left(\mathrm{g} \cdot \mathrm{cm}^{-3}\right)$ & $\mathrm{V}\left(\mathrm{cm}^{3} \cdot \mathrm{mol}^{-1}\right)$ & $\mathrm{V}^{\mathrm{E}}\left(\mathrm{cm}^{3} \cdot \mathrm{mol}^{-1}\right)$ & $\bar{V}_{1}\left(\mathrm{~cm}^{3} \cdot \mathrm{mol}^{-1}\right)$ & $\bar{V}_{2}\left(\mathrm{~cm}^{3} \cdot \mathrm{mol}^{-1}\right)$ \\
\hline 1.0000 & 0.992 & 74.681 & 0.000 & 74.681 & 81.310 \\
\hline 0.9020 & 0.969 & 75.037 & 0.151 & 74.899 & 76.323 \\
\hline 0.8036 & 0.950 & 75.087 & -0.004 & 75.111 & 74.940 \\
\hline 0.7047 & 0.932 & 75.049 & -0.247 & 75.007 & 75.218 \\
\hline 0.6054 & 0.912 & 75.172 & -0.331 & 74.623 & 75.941 \\
\hline 0.5057 & 0.892 & 75.300 & -0.411 & 74.191 & 76.489 \\
\hline 0.4054 & 0.870 & 75.599 & -0.320 & 73.970 & 76.684 \\
\hline 0.3048 & 0.848 & 75.855 & -0.274 & 74.068 & 76.635 \\
\hline 0.2036 & 0.827 & 76.088 & -0.252 & 74.253 & 76.569 \\
\hline 0.1021 & 0.806 & 76.356 & -0.195 & 73.746 & 76.646 \\
\hline 0.0000 & 0.783 & 76.764 & 0.000 & 71.011 & 76.765 \\
\hline
\end{tabular}

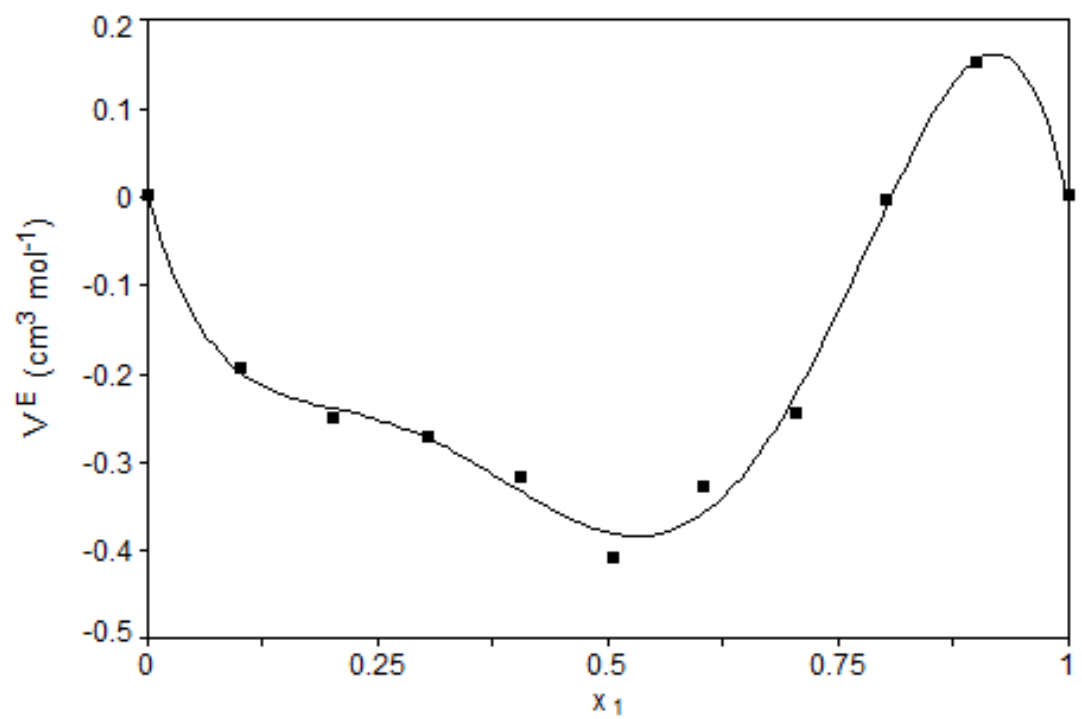

Fig. 2 - Redlich-Kister representation for propanoic acid + 2-propanol binary system. 
Table 3

Experimental results for propanoic acid (1) + 1-butanol (2) binary mixture

\begin{tabular}{c|c|c|c|c|c}
\hline $\mathrm{X}_{1}$ & $\rho_{\text {mix }}\left(\mathrm{g} \cdot \mathrm{cm}^{-3}\right)$ & $\mathrm{V}\left(\mathrm{cm}^{3} \cdot \mathrm{mol}^{-1}\right)$ & $\mathrm{V}^{\mathrm{E}}\left(\mathrm{cm}^{3} \cdot \mathrm{mol}^{-1}\right)$ & $\bar{V}_{1}\left(\mathrm{~cm}^{3} \cdot \mathrm{mol}^{-1}\right)$ & $\bar{V}_{2}\left(\mathrm{~cm}^{3} \cdot \mathrm{mol}^{-1}\right)$ \\
\hline 1.0000 & 0.992 & 74.692 & 0.000 & 74.696 & 89.963 \\
0.9026 & 0.972 & 76.194 & -0.150 & 74.680 & 90.277 \\
0.8009 & 0.952 & 77.818 & -0.252 & 74.629 & 90.571 \\
0.7100 & 0.935 & 79.264 & -0.346 & 74.553 & 90.804 \\
0.5994 & 0.914 & 81.080 & -0.407 & 74.424 & 91.050 \\
0.5004 & 0.895 & 82.753 & -0.413 & 74.273 & 91.234 \\
0.3973 & 0.877 & 84.504 & -0.410 & 74.080 & 91.391 \\
0.3080 & 0.861 & 86.066 & -0.363 & 73.884 & 91.498 \\
0.1967 & 0.842 & 88.055 & -0.262 & 73.602 & 91.593 \\
0.1002 & 0.825 & 89.822 & -0.132 & 73.323 & 91.642 \\
0.0000 & 0.809 & 91.652 & 0.000 & 73.000 & 91.659 \\
\hline
\end{tabular}

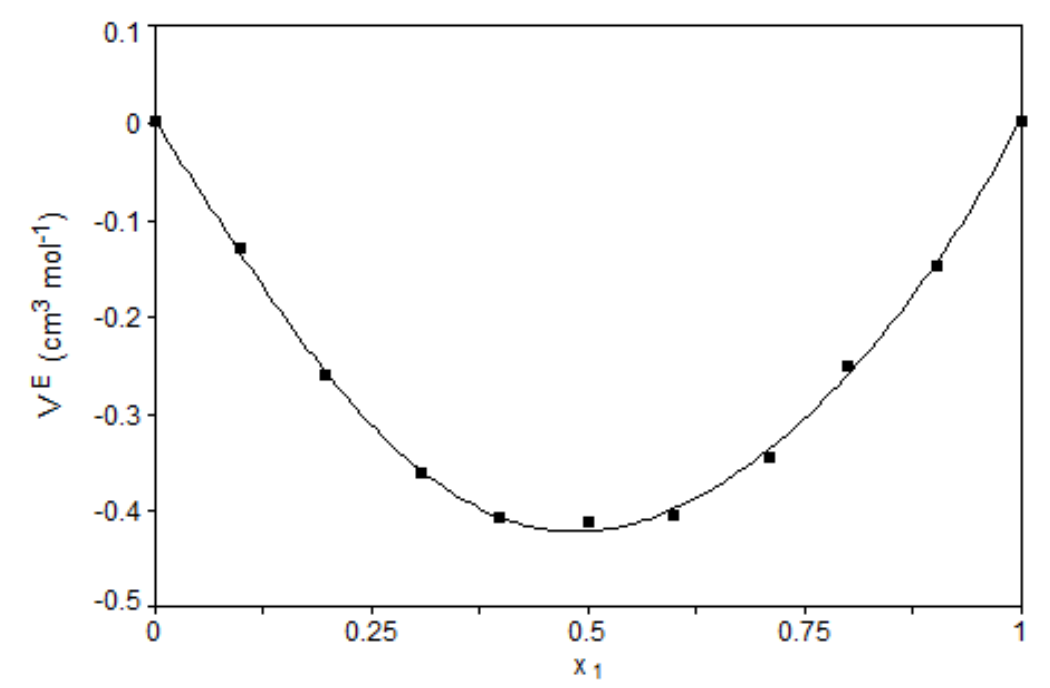

Fig. 3 - Redlich-Kister representation for propanoic acid + 1-butanol binary mixture.

Table 4

Experimental results for propanoic acid (1) + 1-pentanol (2) binary mixture

\begin{tabular}{|c|c|c|c|c|c|}
\hline $\mathrm{x}_{1}$ & $\rho_{\text {mix }}\left(\mathrm{g} \cdot \mathrm{cm}^{-3}\right)$ & $\mathrm{V}\left(\mathrm{cm}^{3} \cdot \mathrm{mol}^{-1}\right)$ & $\mathrm{V}^{\mathrm{E}}\left(\mathrm{cm}^{3} \cdot \mathrm{mol}^{-1}\right)$ & $\bar{V}_{1}\left(\mathrm{~cm}^{3} \cdot \mathrm{mol}^{-1}\right)$ & $\bar{V}_{2}\left(\mathrm{~cm}^{3} \cdot \mathrm{mol}^{-1}\right)$ \\
\hline 1 & 0.992 & 74.661 & 0.000 & 74.632 & 106.959 \\
\hline 0.9038 & 0.970 & 77.729 & -0.184 & 74.618 & 107.235 \\
\hline 0.7989 & 0.947 & 81.180 & -0.276 & 74.571 & 107.504 \\
\hline 0.6992 & 0.927 & 84.498 & -0.329 & 74.496 & 107.730 \\
\hline 0.5910 & 0.906 & 88.110 & -0.374 & 74.380 & 107.940 \\
\hline 0.4907 & 0.888 & 91.471 & -0.404 & 74.241 & 108.104 \\
\hline 0.4011 & 0.873 & 94.540 & -0.364 & 74.091 & 108.224 \\
\hline 0.3054 & 0.857 & 97.832 & -0.303 & 73.905 & 108.326 \\
\hline 0.2032 & 0.841 & 101.365 & -0.227 & 73.675 & 108.405 \\
\hline 0.0935 & 0.826 & 105.165 & -0.133 & 73.393 & 108.454 \\
\hline 0 & 0.813 & 108.460 & 0.000 & 73.124 & 108.467 \\
\hline
\end{tabular}


For propanoic acid + 1-butanol system at $\mathrm{x}_{1}=0.5$ the excess molar volume is similar with literature data $\left(-0.421 \mathrm{~cm}^{3} \cdot \mathrm{mol}^{-1}\right){ }^{13}$

For propanoic acid +1 -pentanol system the excess molar volume decrease very little compared to propanoic acid +1 -butanol system. This means that the length of the chain no longer significantly influences the strength of the hydrogen bond.

The influence of the length of the alcohol chain on the molar excess volumes is shown in Fig. 5.

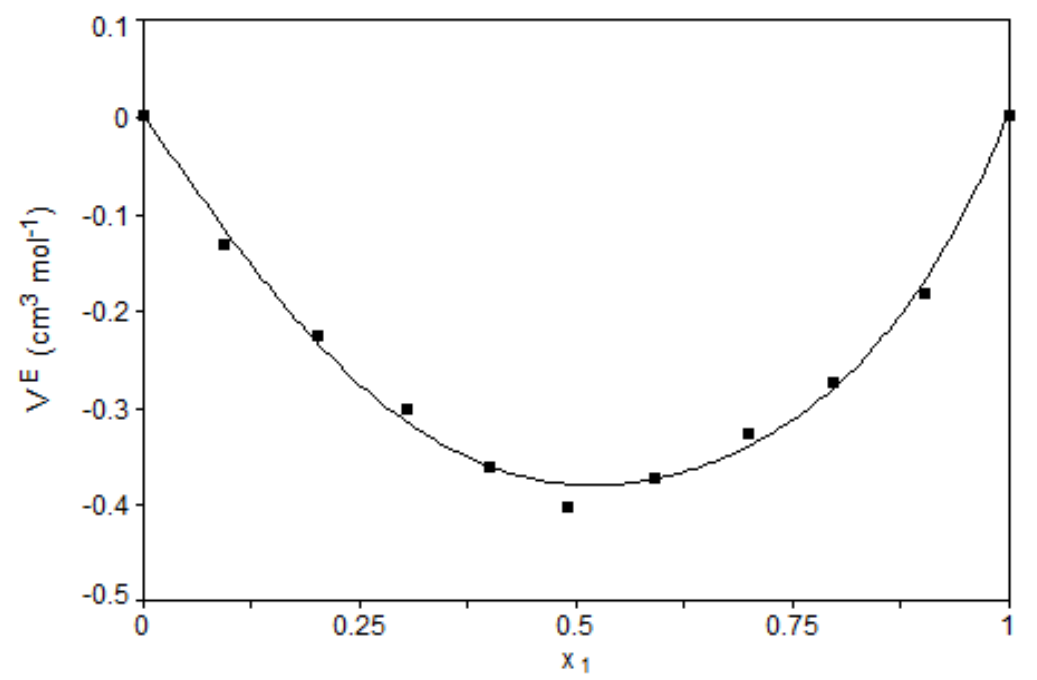

Fig. 4 - Redlich-Kister representation for propanoic acid + 1-pentanol binary system.

Table 5

The Redlich - Kister coefficients for all systems

\begin{tabular}{l|c|c|c|c|c}
\hline System & $\mathbf{A}_{\mathbf{0}}$ & $\mathbf{A}_{\mathbf{1}}$ & $\mathbf{A}_{\mathbf{2}}$ & $\mathbf{A}_{\mathbf{3}}$ & $\mathbf{R}^{\mathbf{2}}$ \\
\hline propanoic acid+1-propanol & -2.6763 & -1.1739 & 0.5685 & 0.8453 & 0.9898 \\
propanoic acid+2-propanol & -1.5276 & 0.5116 & 1.9688 & -4.6084 & 0.9923 \\
propanoic acid + 1-butanol & -1.6947 & -0.1080 & 0.1598 & 0.3138 & 0.9986 \\
propanoic acid+1-pentanol & -1.5267 & 0.1067 & -0.2143 & 0.3878 & 0.9927 \\
\hline
\end{tabular}

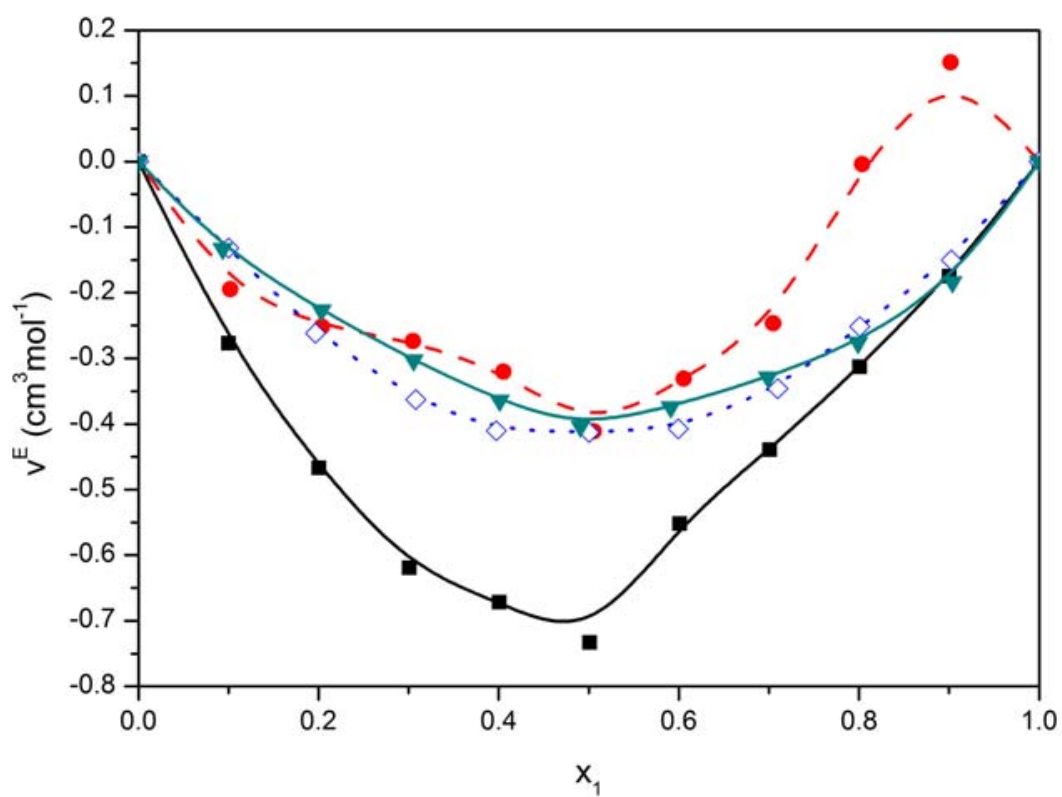

Fig. 5 - Excess molar volumes for binary systems: propanoic acid+1-propanol (•), propanoic acid+2-propanol (•), propanoic acid+1-butanol $(\diamond)$ and propanoic acid+1-pentanol $(\nabla)$. 
From the experimental results it can be said that the strength of hydrogen bond decreases in order: propanoic acid +1-propanol, propanoic acid +1butanol, propanoic acid +1 -pentanol, propanoic acid +2-propanol which means it decreases with increasing the length of the alcohol chain and its branching.

\section{EXPERIMENTAL}

Materials. The propanoic acid (Loba Chemie, purity 99\%), 1propanol (Sigma-Aldrich, purity 99,7\%), 2-propanol (SigmaAldrich, purity $\geq 99,5 \%$ ), 1-butanol (Sigma-Aldrich, purity $99,8 \%$ ) and 1-pentanol (Sigma-Aldrich, purity $\geq 99 \%$ ) were used without further purification.

Apparatus and procedure. All binary mixtures were prepared by mixing the appropriate volume of liquids in a sealed glass vial to prevent evaporation. In this paper, the pycnometric method was used. ${ }^{15}$ The density bottle (pycnometer) calibrated according to ISO 4787 with a volume of $10.334 \mathrm{~cm}^{3}$. The pycnometer was filled with each binary solution and weighed with the Partner XA balance with a precision of $10 \mu \mathrm{g}$. The experimental uncertainty in density was estimated to be less than $\pm 2 \cdot 10^{-5} \mathrm{~g} \cdot \mathrm{cm}^{-3}$.

The excess molar volumes for the binary mixtures were calculated using the formula:

$$
\mathrm{V}^{\mathrm{E}}=\frac{\left(\mathrm{x}_{1} \mathrm{M}_{1}+\mathrm{x}_{2} \mathrm{M}_{2}\right)}{\rho_{\text {mix }}}-\left(\mathrm{x}_{1} \mathrm{~V}_{1}^{\mathrm{o}}+\mathrm{x}_{2} \mathrm{~V}_{2}^{\mathrm{o}}\right)
$$

where $\mathrm{M}_{1}$ and $\mathrm{M}_{2}$ are the molar masses of components 1 and 2 , respectively,

$\rho_{\text {mix }}$ the experimentally density of the liquid mixtures,

$\mathrm{V}_{1}^{\mathrm{o}}$ and $\mathrm{V}_{2}^{\mathrm{o}}$ are the molar volumes of the pure components,

$\mathrm{x}_{1}$ and $\mathrm{x}_{2}$ are the mole fractions

$\rho_{1}$ and $\rho_{2}$, are the density of pure components.

For each system, the partial molar volumes were calculated for alcohol $\left(\bar{V}_{2}\right)$ and for acid $\left(\bar{V}_{1}\right)$ respectively by the method of intercepts ${ }^{16}$ with the relations:

$$
\begin{aligned}
& \bar{V}_{2}=V+x_{1} \frac{\partial V}{\partial x_{2}} \\
& \bar{V}_{1}=V-x_{2} \frac{\partial V}{\partial x_{2}}
\end{aligned}
$$

The excess molar volume was determined by the difference between the molar volume and the ideal molar volume. ${ }^{17-19}$ The excess molar volumes are fitted with the polynomial equations proposed by Redlich and Kister: ${ }^{20-22}$

$$
\mathrm{V}^{\mathrm{E}}=\mathrm{x}_{1}\left(1-\mathrm{x}_{1}\right) \cdot \sum_{\mathrm{i}=0}^{\mathrm{n}} \mathrm{A}_{\mathrm{i}}\left(1-2 \mathrm{x}_{1}\right)^{\mathrm{i}}
$$

where $\mathrm{V}^{\mathrm{E}}$ is the excess molar volume and $\mathrm{A}_{\mathrm{i}}$ represent semiempirical constants and $\mathrm{n}$ is degree of polynomial expansion.

\section{CONCLUSIONS}

The strength of the hydrogen bond decreases with increasing length of the alcohol chain, the excess volumes being smaller, except for the propanoic acid +2-propanol systems which have an atypical behavior.

For the systems propanoic acid +2-propanol, propanoic acid + 1-butanol and propanoic acid +1 pentanol, the excess volumes are approximately equal and highlight the presence of weak attraction forces due to the formation of hydrogen bonds.

The experimental data show that the strength of hydrogen bond decreases in the case of the propanoic acid +2 -propanol mixture compared to the propanoic acid +1 -propanol mixture due to the steric hindrance.

\section{REFERENCES}

1. H.-J. Lee, H.-J. Ahn, C.-S. Kang, J.-C. Choi, H.-J. Choi, K.-G. Lee, J.-I. Kim and H.-Y. Kim, Food Control, 2010, 21, 217-220.

2. S. H. Al-Lahham, M. P. Peppelenbosch, H. Roelofsen, R. J. Vonk and K. Venema, Biochim. Biophys. Acta (BBA), 2010, 1801, 1175-1183.

3. P. Witters, E. Debbold, K. Crivelly, K. VandeKerckhove, K. Corthouts, B. Debbold and E. Morava, Mol. Genet. Metab., 2016, 119, 317-321.

4. N. Longo, L. B. Price, E. Gappmaier, N. L. Cantor, S. L. Ernst, C. Bailey and M. Pasquali, Mol. Genet. Metab., 2017, 122, 51-59.

5. G. Chancel, Compt. Rendus, 1853, 37, 410-412.

6. K. Srirangan, L. Akawi, X. Liu, A. Westbrook, E. J. M. Blondeel, M. G. Aucoin, M. Moo-Young, and C. P. Chou, Biotechnology for Biofuels, 2013, 139, 1-14.

7. A. Wenzel, F. Kornum, M. R. Knudsen and F. F. Lau, Dentomaxillofacial Radiology, 2013, 42, 2-6.

8. G. Debreceni, R. Meggyesi and G. Mestyan, British J. Anaesthesia, 2007, 98, 131-135.

9. L. N. Rodda, J. Beyer, D. Gerostamoulos and O. H. Drummer, Forensic Sci. Med. Pathol., 2013, 9, 194-207.

10. P. Wiśniewska, T. Dymerski, W. Wardencki and J. Namieśnik, J. Sci. Food. Agric., 2014, 95, 2159-2166.

11. R. Sridhar, J. Jeevahan and M. Chandrasekaran, Int. J. Ambient Energy, 2020, 41, 58-63.

12. N. Yilmaz, A. Atmanli, M. Trujillo, Fuel, 2017, 207, 461-469.

13. M. C. S. Subha, K. Chowdoji Rao, G. Narayanaswamy and S. Brahmaji Rao, Phys. Chem. Liq., 1988, 18, 185193.

14. M. Umadevi and A. E. Thomas, Spectrochimica Acta Part A: Molecular and Biomolecular Spectroscopy, 2010, 75, 1181-1190.

15. H. DeVoe, "Thermodynamics and Chemistry", Chapter 9, "Mixtures", Prentice-Hall Inc., 2016, p. 38-39.

16. V. Danek, "Physico-Chemical Analysis of Molten Electrolytes". Elsevier Science, Chapter 5-Density, $1^{\text {st }}$ Edition, 2006, p. 255-269. 
17. P. P. Patil, S. R. Patil, A. U. Borse and D. G. Hundiwale, Rasayan J. Chem., 2011, 3, 599-604.

18. A. R. Mahajan and S. R., Mirgane, J. Thermodynamics, 2013, Vol. 2013, 1-11, Article ID 571918.

19. M. Behroozi and H. Zarei, J. Chem. Eng. Data, 2012, 57, 1089-1094.
20. L. M. Follegatti-Romero, F. H. B. Sosa, M. C. Costa, D. T. Tavares and L. H. de Oliviera, J. Chem. Thermodynamics, 2019, 134, 20-30.

21. A. S. M. Zahid, M. A. Ali and J. R. Hahn, Adv. Appl. Sci. Res., 2015, 6, 65-74.

22. M. Kondaiah, K. Sreekanth, D. S. Kumar and D. K. Rao, J. Solution Chem., 2013, 42, 494-515. 
